\section{'Fish-eye' type concretions: A possible analogue of radionuclide migration and retardation in rock matrices around buried HLW containers}

\section{Hidekazu Yoshida', Nagayoshi Katsuta ${ }^{2}$ and Richard Metcalfe ${ }^{3}$}
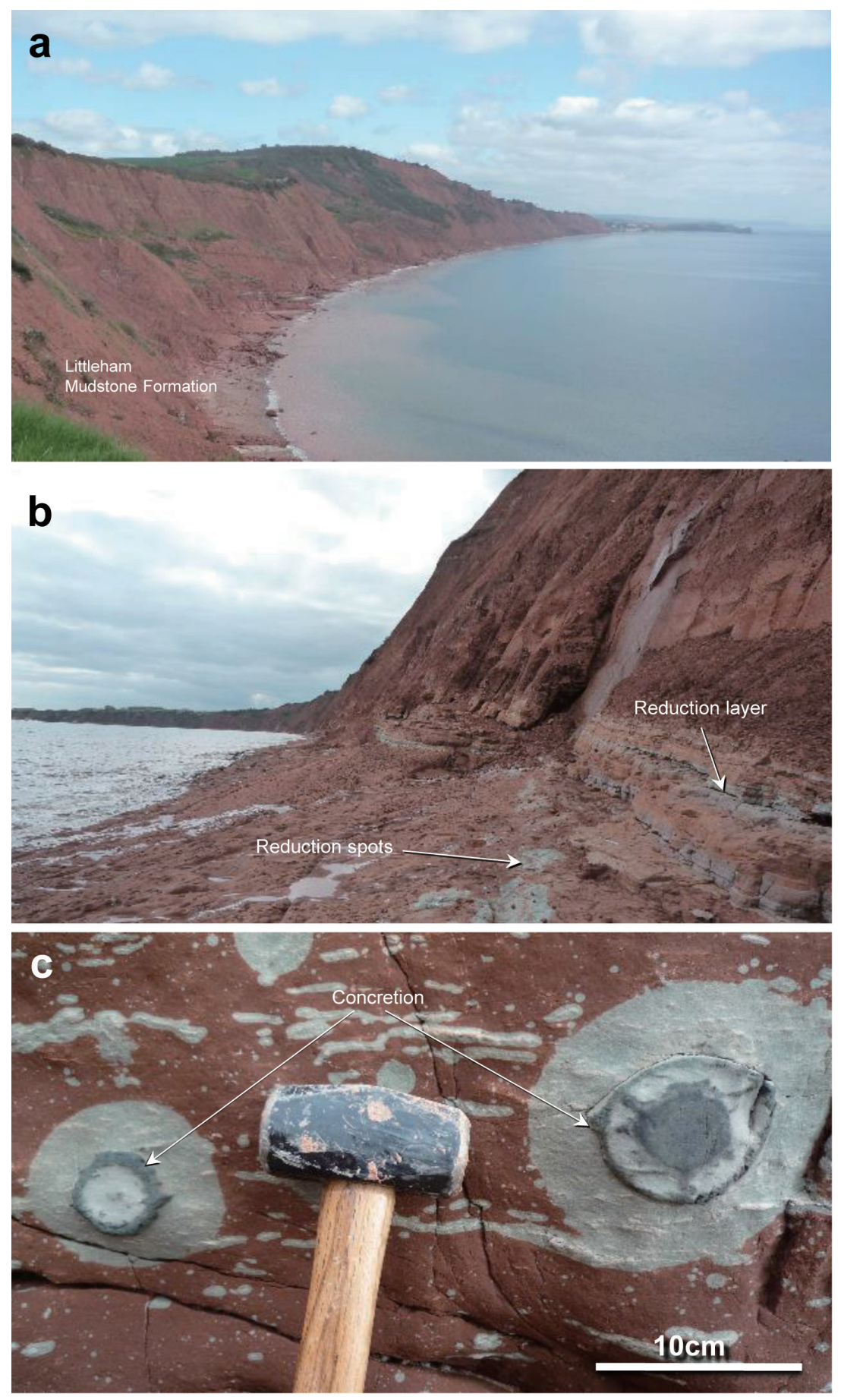

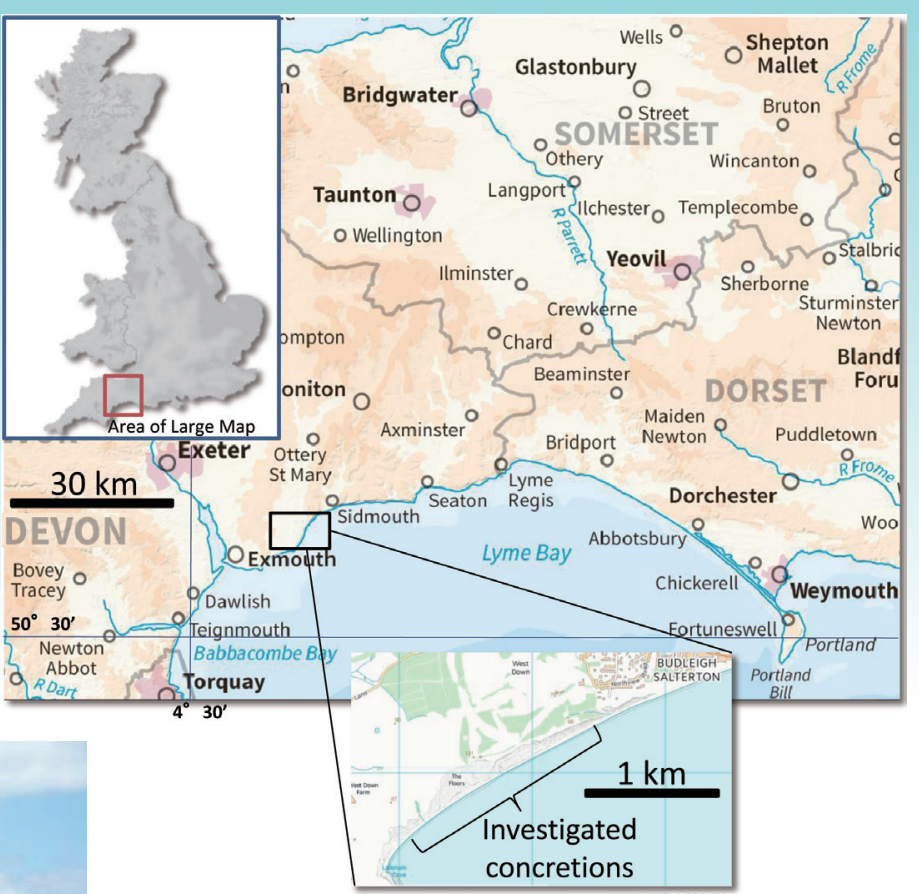

Fig. 1. Location map and sampling points in England (produced from OS OpenData ${ }^{\mathrm{T}}$; contains Ordnance Survey data (C) Crown copyright and database rights 2014).

Received July 10, 2014.

Accepted July 22, 2014.

Nagoya University, University Museum / Graduate School of Environmental Studies, Furocho, Chikusa, Aichi 4648601, Japan

Gifu University, Faculty of Education, Gifu University, 1-1 Yanagito, Gifu 501-1193, Japan

Quintessa Limited, The Hub, Henley-on-Thames, Oxfordshire RG9 1AY, UK

Corresponding author: H. Yoshida, dora@num.nagoya-u.ac.jp

Fig. 2. a; View of the coast from Littleham Cove, Devon, southern England. b; The red Littleham Mudstone contains green to greenish-gray reduced layers and spots (arrows). c; "fish-eye"-type radioactive concretions that are common in the Littleham Mudstone Formation. The larger of these are dark gray spheres, usually a few centimeters in diameter, within a sub-spherical reduced volume ("reduction spot") of pale green mudstone. The internal structure is concentric. The concretions contain enhanced concentrations of uranium, vanadium, and many rare minerals including various arsenides. Native copper also occurs locally (Milodowski et al., 2002). 
Concretions and reduction spots occur in the Permian Littleham Mudstone Formation along the Devon coast in southern England (Fig. 1), just below the boundary with Triassic red beds. The Littleham Mudstone Formation forms part of a red bed sequence of mudstones, sandstones and pebbles beds, which collectively show many characteristics that developed under desert conditions within the supercontinent of Pangaea, including ventifacts, dreikanter and rhizoconcretions. In the coastal section from Littleham Cove eastwards, the Littleham Mudstone Formation contains radioactive concretions that are enriched in a wide variety of metallic elements, includng uranium, vanadium and rare earth elements (REE) (Kemp et al., 1994; Milodowski et al., 2002). These are thought to have formed around fragments of organic matter. According to the reference concept for the geological disposal of high-level radioactive waste (HLW) in Japan, each waste container will be surrounded by a carbon steel over-pack and disposed of in a repository deep underground. Following repository closure, the over-pack will corrode to some extent. Initially the corrosion will be aerobic and consume oxygen trapped within the repository during excavation and operations. Subsequently corrosion will be anaerobic and generate hydrogen. Thus in the long term, conditions in the surrounding host rocks will become reducing. When a waste canister is eventually breached (at least 1000 years, and more likely many thousands of years, after closure) radionuclides that migrate from the waste form will be retarded under the reducing conditions. The processes by which the concretions and reduction spots formed in the Littleham Mudstone Formation can be considered analogous to many of the processes that will occur around the waste canisters. The chemical gradients around the concretions and reductions spots provide evidence of the retardation and concentration of radionuclides in a locally reducing environment within a low-permeability rock through which elements have migrated by diffusion.
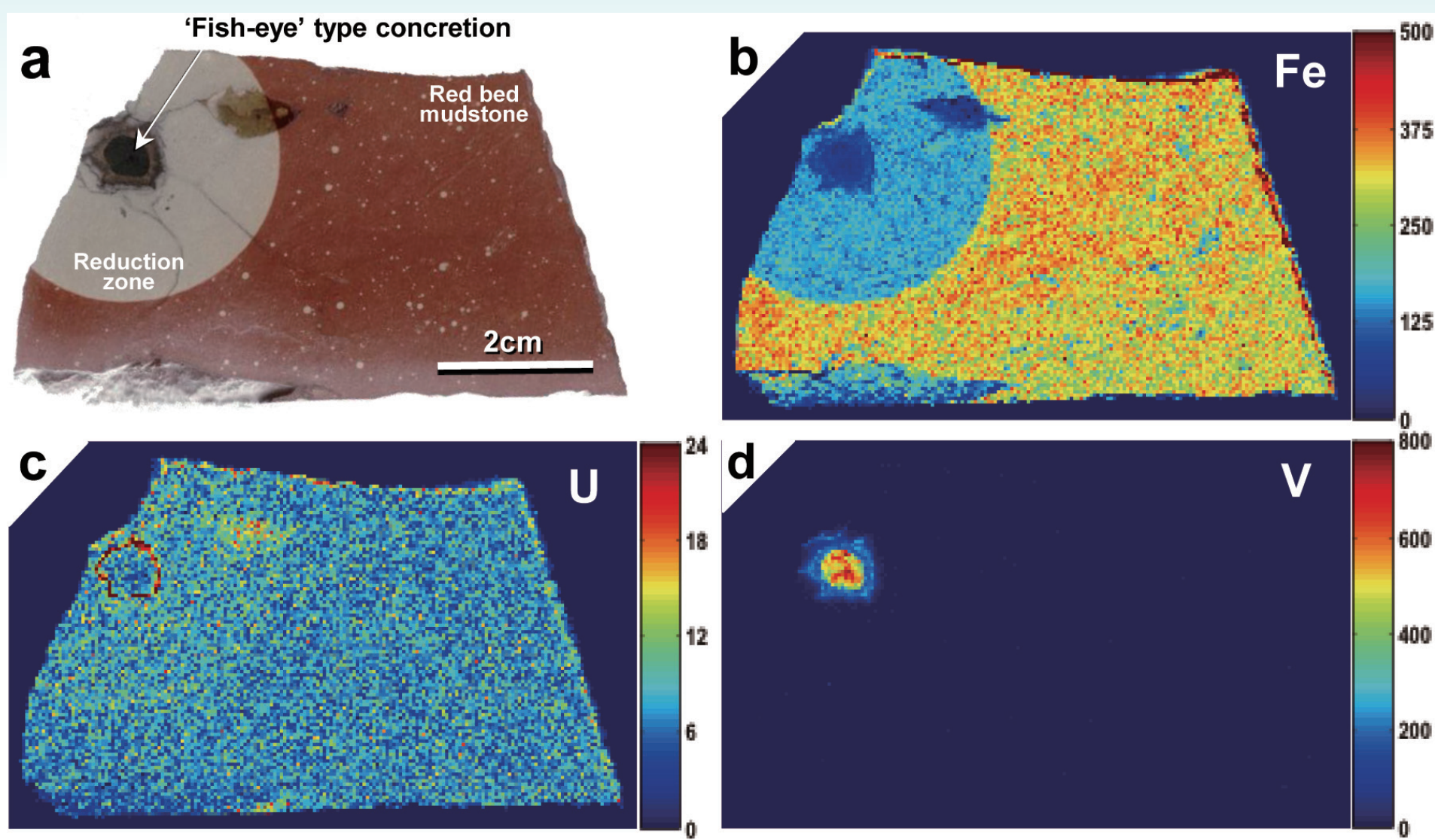

Fig. 3. Preliminary data showing elemental distribution in and around the "fish-eye." a; Polished section of a "fish-eye"-type concretion and redox spot. b-d; X-ray intensities (XGT-2000V Horiba Japan) in and around the redox spot for Fe, V, and U. The Fe map shows the development of a redox halo around the "fish-eye." V and U are closely associated with the "fish-eye," suggesting strong reduction and element fixation within its volume. Reduction has also caused the loss of Fe from the reduction halo. Similar reduction processes might be expected in and around HLW containers due to over-pack corrosion.

\section{References}

Kemp, A. J., Palmer, M. R. and Ragnarsdottir K. V., 1994, The uranium-thorium and rare earth element geochemistry of reduction nodules from Budleigh Salterton, Devon. Proc. Usher Soc., 8, 214-218.

Milodowski, A. E., Styles, M. T., Horstwood, M. S. A. and Kemp S. J., 2002, Alteration of uraniferous and native copper concretions in the Permian mudrocks of south Devon, United Kingdom: A natural analogue study of the corrosion of copper canisters and radiolysis effects in a repository for spent nuclear fuel. Swedish Nuclear Fuel and Waste Management Company (SKB) Report, TR-02-09. 